\title{
THE INFLUENCE OF CARBONIZATION ELIMINATION ON THE ENVIRONMENTAL SAFETY AND EFFICIENCY OF VEHICLE OPERATION
}

\author{
E. MAGARIL \\ Ural Federal University, Russia.
}

\begin{abstract}
Poor quality of motor fuels affects the environmental safety and efficiency of vehicle operation. Solving the problem by modernizing the refinery to raise the quality of petroleum products to the level of modern European standards requires substantial capital investment and cannot be implemented in the short term in Russia and other countries that have a transition economy. The aim of this work is to develop a low-cost method for improving the environmental safety and efficiency of vehicle operation by eliminating carbon formation in engines. It was shown in the theoretical analysis of the influence of carbon on temperature conditions inside the engine, which determines the characteristics performance of engines and the composition of exhaust gases, that the removal of carbon formation leads to a reduction in fuel consumption, toxic emissions, and the requirements of vehicles with gasoline engines for octane number of gasoline used. The method of carbonization elimination has been developed. The effective removal of carbon and significant improvement of the environmental and operational properties of fuels and vehicle characteristics is provided by introducing into the engine fuel in ultra-low quantities the multifunctional additive. The results of extensive research and testing of the additive are presented.
\end{abstract}

Keywords: carbonization, exhaust gas composition, fuel consumption, gasification catalysis, multifunctional additive.

\section{INTRODUCTION}

The reduction of toxic emissions within the exhaust gases of internal combustion engines is one of the greatest challenges to maintaining and improving the environment. The exhaust gases of automobile engines and the high toxicity of substances contained within those gases are a major factor in air pollution, accounting for 80-90\% of the air pollution in many major cities. According to World Health Organization data, three-quarters of human diseases are linked to environmental factors caused by human activities, and transportation is one of the major sources of environmental pollution. The significance of the problem necessitates developing economic methods and instruments to improve the environmental safety of vehicles [1,2], as well as searching for engineering solutions.

The most important factor determining the environmental safety and efficiency of combustion engine operation is the quality of fuels used. Ensuring sustainable development of vehicles with the priorities of environmentally safe and efficient operation requires the solution of problems of modernization of production and optimizing consumption of motor fuels. However, in Russia and some other countries, the lack of capacity for producing high-quality, ecofriendly components of motor fuels leads to a high content of aromatic hydrocarbons in gasoline and polycyclic aromatic hydrocarbons in diesel fuels, which causes increased carbon formation in combustion engines, significantly affecting the environmental safety and operational efficiency of vehicles. Catalytic converters, which are widely used in developed countries, cannot be applied in Russia and some developing countries because of the high sulfur content in the motor fuel produced there. Thus, developing a method to improve the environmental safety and operational performance of vehicles by the removal of carbon deposits in engines, solved in this paper, is the actual task at present. 


\section{THEORETICAL STUDY OF THE INFLUENCE OF ENGINES' CARBONIZATION ON THE OPERATING CHARACTERISTICS OF VEHICLES}

To justify the approach taken to solve the assigned problem, it is necessary to consider the influence of carbonization in the engines on the environmental and operational characteristics of vehicles.

2.1 Influence of carbon formation in the engine on the requirements for the octane number of gasoline used and the fuel's specific consumption

In gasoline engines, during the process of combustion, the burning velocity and temperature of fuel mixture before the flame front continually increase and, respectively, the flame temperature rises. As a result, for a given fuel the flame propagation velocity and pressure, extending from the flame front, increase to a greater extent than does the heat loss transferred to the engine walls, which strongly depends on the temperature of the combustion chamber wall.

Since the engine metal possesses high thermal conductivity, the wall temperature level is similar to the cooling water temperature. However, carbonization greatly reduces heat transfer through the walls. According to Syunyaev [3], carbon deposit is a rapidly heated thermal insulator by its nature because of the thermal conductivity of $1-2 \times 10^{3}$ times smaller than that of metal and heat capacity of three times less than for metal one. Therefore, because of insulating properties even at its smallest thickness, the carbon layer contributes to an increase in the engine wall temperature. After carbonization of the working surfaces of the engine the heat flux transferred to the walls, passes successively through the deposit layer and a layer of metal to the coolant. The heat conduction equation for the process of heat transfer through the cylinder wall after the carbonization may be written as follows:

$$
Q=\lambda_{\text {met }} \frac{\left(T_{\text {met }}-T_{\mathrm{c}}\right)}{l_{\text {met }}} S \tau=\lambda_{\text {dep }} \frac{\left(T_{\text {dep }}-T_{\text {met }}\right)}{l_{\text {dep }}} S \tau
$$

where $T_{\text {met }}, T_{\text {dep }}$ and $T_{\mathrm{c}}$ are the temperatures of the inner surface of the cylinder, making contact with the carbon deposit; a deposit's surface, contacting with chamber volume; a coolant, respectively, $\mathrm{K} ; \lambda_{\text {met }}$ is the thermal conductivity coefficient of a metal of engine's cylinder made from aluminum alloy, which was taken equal to that of aluminum $\lambda_{\text {met }}=\lambda_{\mathrm{Al}}=2.18 \mathrm{~J} / \mathrm{cm} \cdot \mathrm{s} \cdot \mathrm{K}$ [4]; $\lambda_{\text {dep }}$ is the thermal conductivity coefficient of a carbon deposit, $\mathrm{J} / \mathrm{cm} \cdot \mathrm{s} ; l_{\text {met }}$ and $l_{\text {dep }}$ are the thickness of the cylinder wall and deposit layer, respectively, $\mathrm{cm} ; S$ is the surface area of cylinder wall; $\tau$ is the time, s. From eqn (1), the wall temperature after carbon deposition $\left(T_{\text {dep }}\right)$ may be calculated as follows:

$$
T_{\text {dep }}=T_{\text {met }}\left(1+\frac{l_{\text {dep }} \cdot \lambda_{\text {met }}}{\lambda_{\text {dep }} \cdot l_{\text {met }}}\right)-\frac{l_{\text {dep }} \cdot \lambda_{\text {met }}}{\lambda_{\text {dep }} \cdot l_{\text {met }}} T_{\mathrm{c}}
$$

The coefficient of thermal conductivity of carbon deposit was determined under its phase composition. X-ray diffraction analysis of samples of sludge taken from the internal walls of gasoline engines revealed a significant proportion of the carbon content in the amorphous state, as well as its presence in primary crystalline structures. The author assumed the value of the thermal conductivity of polycrystalline carbon be equal to its value of graphite. Suppose the fraction of carbon in the amorphous state is $50 \%$, then as $\lambda_{\mathrm{C}}$ (amorphous) $=0.0017 \mathrm{~J} / \mathrm{cm} \cdot \mathrm{s} \cdot \mathrm{K}, \lambda_{\mathrm{C}}$ (graphite) $=0.049 \mathrm{~J} / \mathrm{cm} \cdot \mathrm{s} \cdot \mathrm{K}$ [5], the thermal conductivity of carbon deposit $\lambda_{\text {dep }}=0.5 \lambda_{\mathrm{C}}$ (amorphous) $+0.5 \lambda_{\mathrm{C}}$ (graphite) $=0.025 \mathrm{~J} / \mathrm{cm} \cdot \mathrm{s} \cdot \mathrm{K}$.

From eqn (2), the temperature of the carbon deposit layer was determined dependent on its thickness and coolant temperature. As is evident from the results of the calculations presented in Table 1, with the growth of the carbon deposit layer the cylinder wall temperature significantly increases. 
Table 1: The temperature of the engine cylinder inner wall $\left(l_{\text {met }}=0.6 \mathrm{~cm}\right)$ before and after carbonization, $\mathrm{K}$.

\begin{tabular}{|c|c|c|c|c|c|c|c|c|c|c|}
\hline \multirow[t]{2}{*}{$\begin{array}{l}\text { Clean } \\
\text { wall }\end{array}$} & \multicolumn{5}{|c|}{$\begin{array}{c}l_{\mathrm{dep}}=0.01 \mathrm{~cm} \\
T_{\mathrm{c}}(\mathrm{K})\end{array}$} & \multicolumn{5}{|c|}{$\begin{array}{c}l_{\mathrm{dep}}=0.02 \mathrm{~cm} \\
T_{\mathrm{c}}(\mathrm{K})\end{array}$} \\
\hline & 358 & 362 & 368 & 373 & 378 & 358 & 362 & 368 & 373 & 378 \\
\hline 423 & 517 & 510 & 503 & 496 & 488 & 612 & 597 & 583 & 568 & 554 \\
\hline 448 & 579 & 571 & 564 & 557 & 550 & 709 & 695 & 680 & 666 & 651 \\
\hline 473 & 640 & 633 & 626 & 618 & 611 & 807 & 793 & 778 & 764 & 749 \\
\hline 498 & 701 & 694 & 687 & 680 & 672 & 905 & 890 & 876 & 861 & 847 \\
\hline 523 & 763 & 755 & 748 & 741 & 734 & 1002 & 988 & 973 & 959 & 944 \\
\hline
\end{tabular}

Heat rejection by radiation from the volume of the combustion chamber to the wall is described by the Stefan-Boltzmann law [6-9]:

$$
Q_{\mathrm{rad}}=\left(\varepsilon_{1}\left(\frac{T_{1}}{100}\right)^{4}-\varepsilon_{2}\left(\frac{T_{2}}{100}\right)^{4}\right) \cdot S \cdot \tau
$$

where $\varepsilon_{1}$ and $\varepsilon_{2}$ are the emissivity coefficients of the radiating and absorbing body, respectively; $T_{1}$ and $T_{2}$ are the temperatures of the radiating and absorbing body, respectively, $\mathrm{K} ; S$ is the surface area of the radiating body, $\mathrm{cm}^{2} ; \tau$ is the time, $\mathrm{s}$.

From eqn (3), the ratio of the heat transferred by radiation to the wall with and without carbon deposit is given by

$$
\frac{Q_{\text {rad }}^{\text {dep }}}{Q_{\text {rad }}^{\text {met }}}=\frac{\left(\varepsilon_{\mathrm{f}}\left(\frac{T_{\mathrm{f}}}{100}\right)^{4}-\varepsilon_{\text {dep }}\left(\frac{T_{\text {dep }}}{100}\right)^{4}\right)}{\left(\varepsilon_{\mathrm{f}}\left(\frac{T_{\mathrm{f}}}{100}\right)^{4}-\varepsilon_{\text {met }}\left(\frac{T_{\text {met }}}{100}\right)^{4}\right)}
$$

where $\varepsilon_{\mathrm{f}}, \varepsilon_{\mathrm{met}}$, and $\varepsilon_{\mathrm{dep}}$ are the emissivity coefficients of the flame, clean metallic wall, and carbon deposit, respectively; $T_{\mathrm{f}}, T_{\mathrm{met}}$ and $T_{\mathrm{dep}}$ are the temperatures of the flame, clean wall, and carbon deposit, respectively, K. It was assumed that $\varepsilon_{\mathrm{f}}=\varepsilon_{\text {met }}=0.5, \varepsilon_{\text {dep }}=0.95$ [9].

The results of the calculations of the influence of carbonization on the heat radiation from the volume of the combustion chamber to the cylinder wall depending on the thickness of its layer and temperature of the inner surface of clean wall are presented in Fig. 1. Thus, because of the formation of carbon deposits on the cylinder walls due to the reduction of heat removal from the inner surface of the combustion chamber walls to the coolant and the increase in wall temperature, quantity of heat transferred from the volume of the combustion chamber to the walls reduces by $5-10 \%$ and more. As a result, the maximum temperature in the cylinder rises.

In addition, carbon deposit, as a reaction-active substance, inclines to self-ignition at $330-360^{\circ} \mathrm{C}$. Scorching during the burning of fuel mixture and emission of the products of combustion, carbon deposit, due to its low thermal conductivity, keeps the heat and propensity to interact with oxygen in 


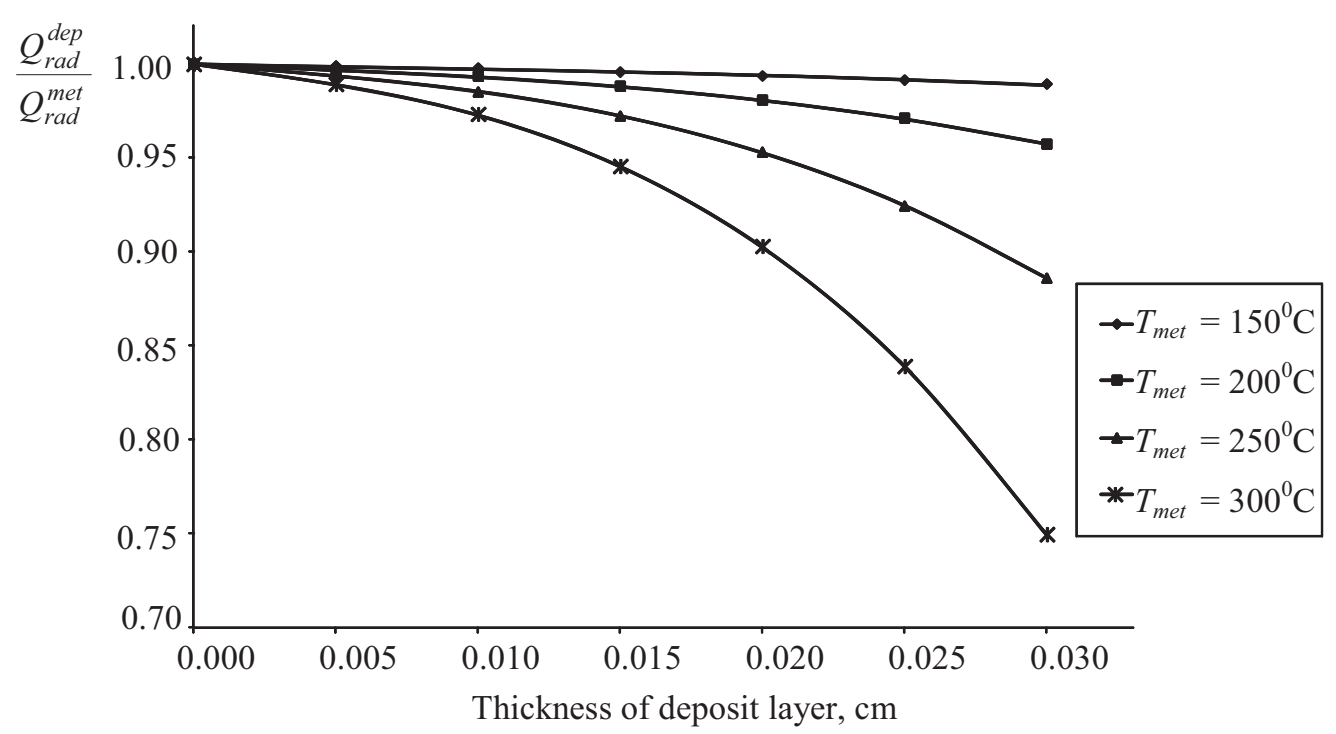

Figure 1: Influence of carbon deposit on heat removal from the volume of the combustion chamber to the walls $\left(T_{\mathrm{c}}=95^{\circ} \mathrm{C}\right)$.

the inlet fuel with the formation of 'hot spots' causing the initiation of combustion before sparking. The 'surface ignition' appears. Premature combustion in the compression stroke, in turn, leads to a significant increase in energy consumption for compression, an increase in fuel consumption and a reduction in engine power. As a result of surface ignition, the heating rate of the combustible mixture in the compression stroke rises and that creates an additional opportunity for detonation in gasoline engines.

To avoid detonation during operation of a gasoline engine with the accumulation of carbon in the combustion chamber and the attainment of some equilibrium in its thickness, the required octane level of gasoline should be increased, as it is known, for 10 or more points [10, 11].

This is due to an increase in the rate of reaction according to the Arrhenius equation and, more importantly, an increase in the concentration of ions, electron-excited molecules and radicals.

In addition, the carbonization on the working surfaces of the engine significantly increases the friction that leads to the growth of the fuel specific consumption and the reduction of engine power.

Therefore, because of mitigation of the temperature regime in the engine, removal of carbonization will reduce the requirements for the octane number of gasoline used by up to 10 points and will increase the power of gasoline and diesel engines and reduce fuel specific consumption.

\subsection{The influence of carbonization on the composition of exhaust gases of automobile engines}

In order to study the influence of carbonization in engines on the environmental performance of vehicles the kinetics of NO formation in engine exhaust gases was analyzed. Nitric oxide (II) is produced in the engine according to the reaction:

$$
\mathrm{N}_{2}+\mathrm{O}_{2} \rightleftarrows 2 \mathrm{NO}-181 \mathrm{KJ}
$$

Taking into account the kinetic data provided by Kondratiev [12], the change in the rate of direct reaction and the equilibrium concentration of nitric oxide (II) at low temperatures was estimated, 
assuming that the concentration of nitrogen and oxygen in the gas mixture at different temperatures is the same. From the results of calculations presented in Table 2 it follows that with a decrease in temperature the rate of $\mathrm{NO}$ formation sharply decreases and the equilibrium concentration of $\mathrm{NO}$ with a strong dependence of the equilibrium constant on temperature also drops rapidly. It should be noted that this analysis does not take into account local factors in the engine and demonstrates the general regularities of the formation of nitric oxide in the engine with a change in the maximum temperature.

In the fuel combustion process, with stoichiometric air-fuel ratio $(\alpha=1)$ and the excess of oxygen $(\alpha>1)$, the content of carbon monoxide in the exhaust gas is determined by the dissociation of carbon dioxide at the peak temperatures reached in the engine. Under the pressure of $1 \mathrm{MPa}$ in the products of hydrocarbons' combustion in oxygen, the concentration of carbon monoxide in an equilibrium mixture varies from 18 vol. $\%$ at $2000 \mathrm{~K}$ to $23 \mathrm{vol} . \%$ at $3000 \mathrm{~K}[13,14]$. At the peak flame temperature, the concentration of carbon monoxide reaches the higher value, and the higher the temperature, the higher the value. Behind the flame front carbon monoxide oxidizes to the dioxide, but with decreasing temperature the reaction rate decreases rapidly and the reaction becomes 'frozen'. Thus, the removal of carbon deposit in the engine, which significantly decreases the peak temperature in the combustion chamber, would substantially reduce emissions from oxides of nitrogen and carbon within the exhaust gases. Furthermore, the removal of carbon deposit in gasoline engines is accompanied by the almost complete elimination of emission of polycyclic aromatic hydrocarbons, precursors of carbon deposit, including benzo(a)pyrene, one of the strongest carcinogens. It should also be noted that the reduction of the fuel specific consumption will lead to a corresponding reduction in the emission and the amount of 'greenhouse gases' $\left(\mathrm{CO}_{2}, \mathrm{CH}_{4}\right.$, etc.).

\subsection{Patterns of accumulation of carbon deposit in engines}

Considering the conditions of carbon deposit formation in the engine (low temperature of the wall), the accumulation of carbonization with gasoline reaching boiling point (end point of boiling $90 \%$ of gasoline) and with an increase in the level of unsaturated and aromatic hydrocarbons within it, and also with a rising level of polycyclic aromatic hydrocarbons in diesel fuel, and a high hydrogen content in the carbon deposit (carbon content is in the range of 70-75\%), we suggest that carbon deposit is formed in the wall boundary layer in accordance with the mechanism of coke formation $[14,15]$.

Table 2: The change of reaction rate of NO formation and its concentration in equilibrium mixture dependent on the maximal temperature in the engine (where $k_{v}^{T}$ is the reaction rate constant of $\mathrm{N}_{2}+\mathrm{O}_{2} \rightarrow 2 \mathrm{NO}, v^{T}$ is the reaction rate, $k_{e q}^{T}$ is the equilibrium constant, $\mathrm{c}_{N O}^{T}$ is the equilibrium concentration of $\mathrm{NO}$ at temperature $T$ ).

\begin{tabular}{lcccc}
\hline$T(\mathrm{~K})$ & $k_{v}^{T}\left(\mathrm{~cm}^{3} / \mathrm{mol} \mathrm{s}\right)$ & $\frac{k_{\mathrm{v}}^{\mathrm{T}}}{k_{v}^{2500}}=\frac{v^{\mathrm{T}}}{v^{2500}}$ & $k_{e q}^{T}$ & $\sqrt{\frac{k_{\mathrm{eq}}^{\mathrm{T}}}{k_{\text {eq }}^{2500}}}=\frac{c_{\mathrm{NO}}^{\mathrm{T}}}{c_{\mathrm{NO}}^{2500}}$ \\
\hline 2500 & $10^{5.21}$ & 1 & $10^{-2.31 \pm 0.30}$ & 1 \\
2250 & $10^{4.08}$ & 0.074 & $10^{-2.71 \pm 0.31}$ & $0.40 \pm 0.01$ \\
2000 & $10^{-1.14}$ & $4.5 \times 10^{-7}$ & $10^{-3.17 \pm 0.33}$ & $0.14 \pm 0.01$ \\
\hline
\end{tabular}


The probability of getting drops of fuel on the wall, which may be the cause of an increase in the carbon formation, reduces with the improvement of mixing in the engine. As a result of the introduction of surfactant in fuel, the surface tension of fuel on the boundary with air decreases, resulting in reduced fuel droplet size, which increases their total surface and the evaporation rate. Consequently, the number of carbon deposits formed in the engine can be reduced by the introduction of fuel surfactants. Simultaneously with the deposit formation, its gasification and oxidation take place:

$$
\begin{gathered}
\mathrm{C}+\mathrm{H}_{2} \mathrm{O} \rightarrow \mathrm{CO}+\mathrm{H}_{2}, \\
\mathrm{C}+\mathrm{CO}_{2} \rightarrow \mathrm{CO}, \\
\mathrm{C}+\mathrm{O}_{2} \rightarrow \mathrm{CO} .
\end{gathered}
$$

Therefore, the amount of carbon deposit in the combustion chamber depends on the ratio of the rates of parallel reactions of carbon formation on the one hand, and the gasification and oxidation of carbon on the other. Thus, during operation of the engine, certain equilibrium in the thickness of the deposit will be reached over time, which depends on the quality of fuel used.

Thereby, the catalytic acceleration of the reactions of gasification and oxidation of carbon in the engine could be considerably useful for improving environmental safety and operational efficiency of cars.

\section{THE BACKGROUND OF THE METHOD OF ENGINE CARBONIZATION REMOVAL} The theoretical analysis presented in Chapter 2 shows that the removal of carbonization in the engine will have a significant positive impact on the environmental and operational characteristics of vehicle under conditions of the high-quality fuel's utilization as well. In principle, the process of engine carbonization suppression, which could be proposed on the background of theoretical analysis, is the introduction into the engine in minimal amounts of a fuel soluble compound - the fuel additive, which has surfactant properties and contains an element that has high catalytic activity in redox reactions.

To base the composition of the fuel additive, which could be active in carbon deposit suppression in engines, we endeavored to find an all-purpose, multifunctional additive for gasoline and diesel fuels that not only had anti-carbonization action but also provided a comprehensive positive effect on the properties of fuels and the characteristics of engines. It should be noted that petroleumrefining methods cannot provide the necessary level of such fuel characteristics as the cleaning and lubricating properties achieved by using appropriate additives for fuels. On the basis of theoretical studies of the influence of fuel quality on the performance of motor transport [13, 14], we have formulated the requirements to the properties of additives that can improve the environmental performance of vehicle [16]:

- suppression of carbonization in engines;

- improved inlet mixture formation in engines;

- decrease in unburned combustibles' emission;

- decrease of emissions from oxides of nitrogen and carbon;

- decrease of soot emissions;

- enhancement of the detergent properties of fuels;

- increase in the cetane number of diesel fuels;

- improvement in the low-temperature properties of diesel fuels;

- increase in the wear-resistant properties of diesel fuels;

- good solubility of additive in fuels under all operating conditions; 
- the absence of additional emissions of toxic substances that are not generated when using fuel without additives; and

- accessibility and low cost of raw materials.

Based on the stated requirements and screening of the data on the catalytic and physical-chemical properties of substances, the composition of an oil-soluble multifunctional additive and the technology of its production were developed $[13,15]$, and its optimal concentration in fuel of $9.25 \mathrm{ppm}$ for gasoline and $27.75 \mathrm{ppm}$ for diesel fuel was found.

The additive is synthesized from available, low-cost components and its production does not require highly qualified specialists and sophisticated equipment. The additive may be introduced into the fuel at any stage of its production, at the petrol stations and directly into the fuel tanks of vehicles.

\section{THE RESULTS OF THE ADDITIVE APPLICATION}

The developed method of carbonization elimination in the engine by introducing a highly effective multifunctional additive into the fuel was assessed with comprehensive identity verification. The additive was thoroughly tested in the laboratory, in bench tests and in road tests. The tests were performed by standard methods of State Standard Specification of Russia and the UNECE. The atomic-absorption analysis of content showed no additional toxic components in exhaust gases, unobserved before the application of the additive. The high efficiency of the developed additive was confirmed with experimental-industrial checkout. Well-known and commonly used monofunctional additives are significantly less efficient than that proposed, at a consumption rate of 20-100 times higher and are considerably more expensive. The additive was used in the production of about 360 thousand tons of gasoline and 40 thousand tons of diesel fuel.

\subsection{The influence of the additive on carbonization in engines}

The studies of the influence of the multifunctional additive on the process of an engine's carbonization showed that the additive concentration of $9.25 \cdot \mathrm{ppm}$ in gasoline and $27.75 \mathrm{ppm}$ in diesel fuel was enough to eliminate carbon deposits almost completely. The testing of the influence of the additive on the fuel consumption on a diesel engine of locomotive 2TE116 No. 42 (the engine peak brake power is $2250 \mathrm{~kW}$, the fuel consumption by diesel engine under pick load $205 \mathrm{~g} / \mathrm{kW} \cdot \mathrm{h}$, mass of dry diesel is $17,650 \mathrm{~kg}$ ) showed that the reduction of the fuel consumption after 9 hours of operation on fuel with the additive was $6.9 \%$. The combustion chamber of one of the cylinders was unsealed before and after the testing run on fuel with the additive. It was found that the amount of carbon deposit in the combustion chamber on the valves and piston crown decreased sharply (Fig. 2).

The influence of the additive on the fuel specific consumption during the road tests in the countryside in constant speed mode $(\sim 90 \mathrm{~km} / \mathrm{h})$ was investigated. Tests were performed under the constant weather conditions (air temperature, barometric pressure, and relative humidity) before and after the application of additive. Technical checkout of the engines of vehicles of different brands, which had traveled 20,000 km before the inspection, after the road tests with the gasoline modified with the additive, showed a significant purification of spark plugs, valves, and cylinder-piston group of the testing vehicles from carbon deposits. As an example in Fig. 3, the pictures of the Nexia SOHC engines of UZ-Daewoo's vehicles (the engine peak brake power is $59 \mathrm{~kW} / 5600$ turns/min, fuel consumption in composite cycle is $7.51 / 100 \mathrm{~km}$, fully loaded mass is $1460 \mathrm{~kg}$ ) after the application of the additive are presented. Specific consumption of gasoline with the additive decreased by $5-12 \%$ 


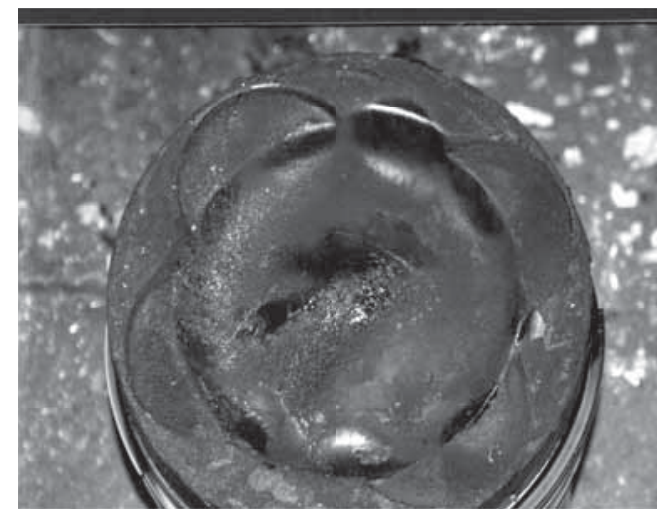

a)

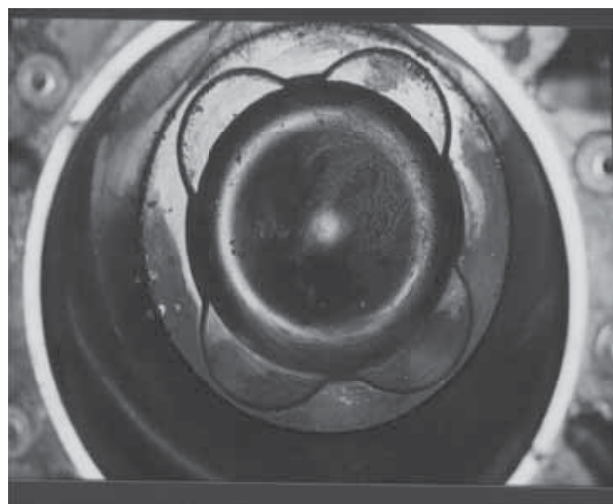

b)

Figure 2: The outside of the piston's crown of diesel engine of locomotive 2TE116 No. 42. (a) Before the additive application and (b) after 9 hours of testing run on fuel with the additive.

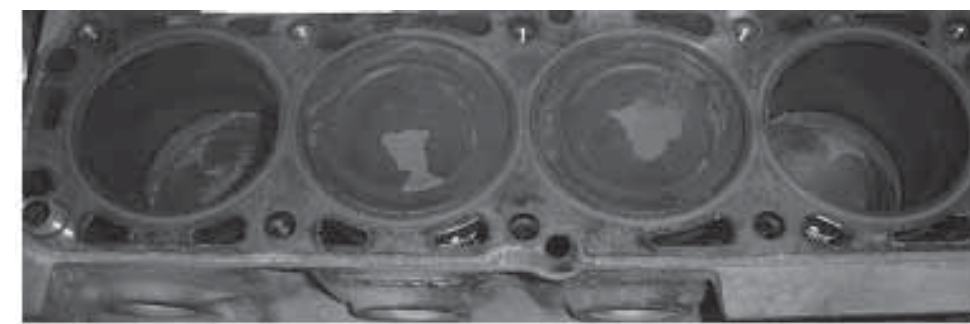

a)

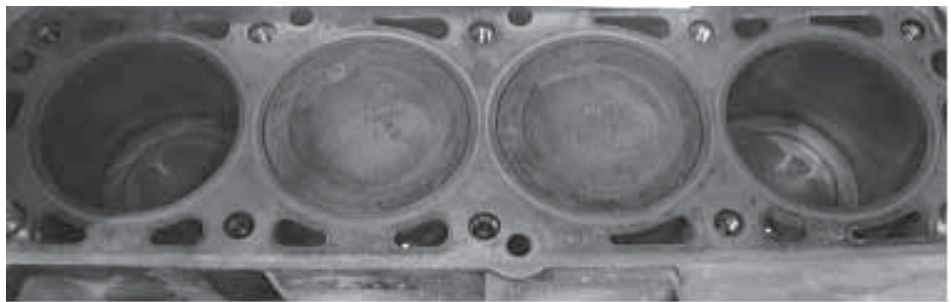

b)

Figure 3: The outside of cylinder-piston group of Nexia SOHC engines of UZ-Daewoo's vehicles after the testing run of $1935 \mathrm{~km}$. (a) Controlling vehicle and (b) testing vehicle after the run with the application of the additive.

for the different vehicles. Requirements for the octane number of gasoline after applying the additive decreased by $6-10$ points [16].

Microscopic examination of samples, prepared from the electrodes of spark plugs (cross-section) of the automobile VAZ 2110, engine VAZ 2111 was performed by optic microscope Olympus GX-71. The pictures, presented on Fig. 4, demonstrate that after the testing run on the gasoline with the additive the carbon deposit is eliminated almost completely and 'smoothing' of the electrode surface takes place. 


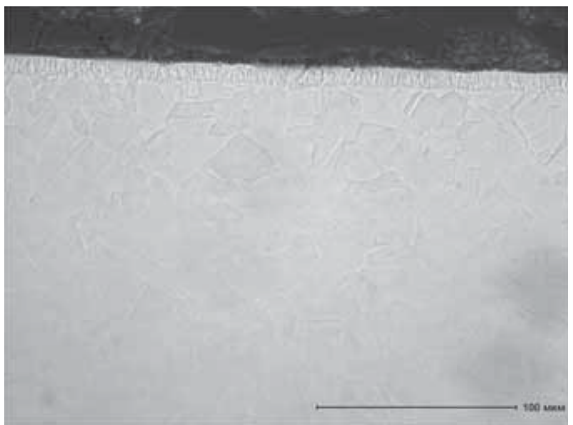

a)

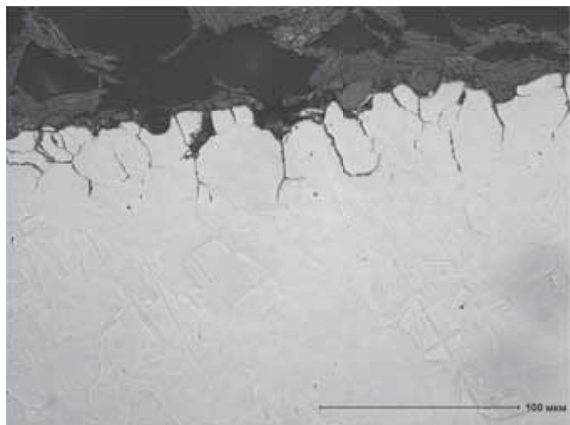

b)

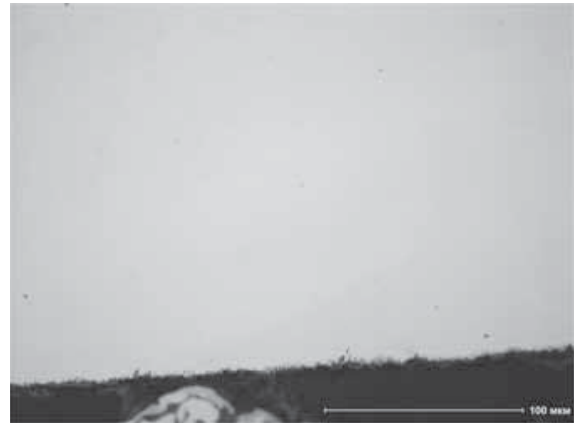

c)

Figure 4: Microstructures of the samples prepared from the electrodes of spark plugs (500 times zooming). (a) A new spark plug, (b) the spark plug with the carbon deposit layer, and (c) the spark plug after daily running on gasoline with the additive.

4.2 The influence of the additive on the mixture formation and fuel losses from evaporation of gasoline

The author's studies showed that the additive reduced both the surface tension at the fuel-air interface and the saturated vapor pressure (SVP) of gasoline (Fig. 5). It provides valuable technical results - reduction of fuel loss through evaporation of gasoline, and at the same time - the improvement of the inlet mixture formation of both gasoline and diesel fuel engines.

It should be noted that the loss through evaporation of gasoline on the way to the "producercombustion chamber' reaches $1.5-2.0 \%$, and a big part of hydrocarbons emitted by vehicles $(15-40 \%)$ is the vapor loss from a vehicle's fuel system. It confirms the significant environmental importance of the surface-active effect of the additive. In addition, the decrease of SVP as a result of the additive introduction allows for an increase in the concentration of butanes in gasoline - highoctane and environmentally friendly gasoline components.

4.3 The influence of the additive on the emission of toxic substances with burnt gases

The influence of the additive on the emission of benzo(a)pyrene by vehicles with gasoline engines idling was investigated. It was found that the reduction of the emission of polycyclic aromatic 


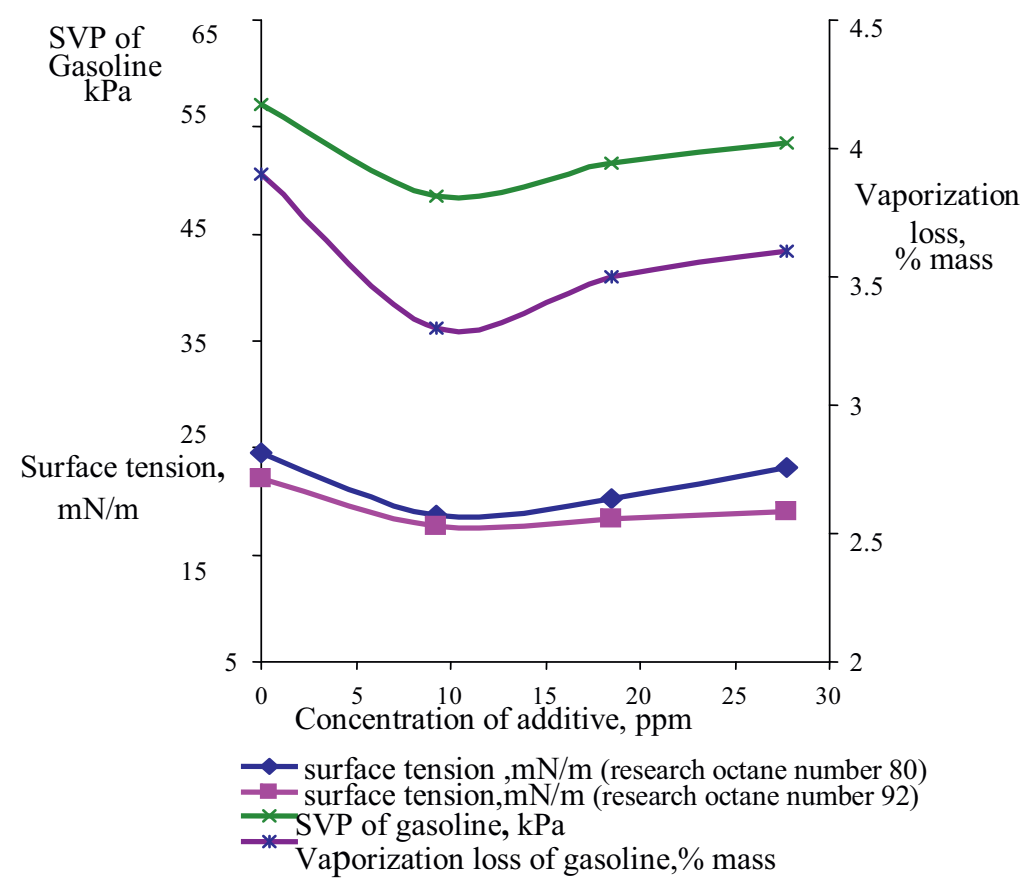

Figure 5: The influence of the additive on the value of surface tension at the $15^{\circ} \mathrm{C}$, on the saturated vapor pressure of gasoline and the vaporization loss of gasoline.

Table 3: Influence of the additive on the emission of benzo(a)pyrene and other polycyclic aromatic hydrocarbons. Vehicle GAZ-3102, idling test.

Content in burnt gases $\left(\mathrm{mg} / \mathrm{m}^{3}\right)$

\begin{tabular}{lcc} 
Gasoline & Benzo(a)pyrene & $\begin{array}{r}\text { Scope of multiring aromatc } \\
\text { lighter }\end{array}$ \\
\hline Without additive & 0.00023 & 0.00583 \\
With additive & 0.00001 & 0.00030 \\
Change $(\%)$ & -95.7 & -94.9
\end{tabular}

hydrocarbons was $\sim 95 \%$ (Table 3), which increases durability of the exhaust catalytic converters as well as hugely reducing the environmental impact of vehicles without catalytic converters.

Removal of carbonization affects on the emissions of other toxic substances. Some test results for vehicles with petrol engines are shown in Table 4.

The additive is a catalyst for the reaction $\mathrm{CO}+\mathrm{NO} \rightarrow \mathrm{CO}_{2}+\mathrm{N}_{2}$. At a sufficiently high concentration of $\mathrm{CO}(\alpha=0,98 \div 1)$ under the influence of the additive nitrogen oxide emissions as a result of this reaction reduce considerably. The concentration of $\mathrm{CO}$ at $\alpha>1$ is low and nitrogen oxide emission with the introduction of the additive does not change, but $\mathrm{CO}$ emission reduces significantly. Checks on the 
influence of the additive on the emissions of toxic substances in exhaust gases of diesel engines were carried out on the bench diesel engine ZIL-645 in the bureau of working processes and toxicity of ZIL company in agreement with UNECE's guidance No. 49 with 13-step cycle starting with the engine warm. Table 5 presents the results of the influence of the additive on the emission of toxic substances in the cycle. Under full load the soot content in the exhaust gas decreased by $50 \%$ - from 0.36 to 0.18 $\mathrm{mg} / \mathrm{L}$. The application of the additive has reduced the emissions of $\mathrm{CO}, \mathrm{CH}$, and $\mathrm{NO}_{2}$ by 14.6, 37.2, and $20.6 \%$, respectively. The additive reduces the toxicity of emissions at all operation regimes of the diesel engine. Figure 6 presents the data about the influence of the additive on the opacity of exhaust gases. The use of the additive reduces the opacity of exhaust gases on 18.4-44.0\%.

In tests on different diesel engines, a decrease in fuel consumption by 4-7\% was registered. Further research showed the connection of this effect not only to the anti-deposit's properties of the additive and improvement of the inlet mixture formation but also to an increase in the cetane number.

It should be noted that the additives known in the world market, which reduce the toxicity of exhaust gases, give the same effect as the developed additive but with concentrations 50-100 times higher. The analogs with the influence on benzo( $\alpha)$ pyrene emissions are unknown.

\subsection{The influence of the additive on the detergent properties of fuel}

To facilitate undisturbed operation of the fuel systems of gasoline and diesel engines, high detergent properties of fuel are necessary, and the application of the detergent additives to gasoline within developed countries is required. The developed additive is more effective than the best detergents available on the world market. Table 6 presents data on the effect of various additives on the detergent properties of gasoline.

Table 4: Influence of the additive on the emissions of toxic substances in bench test running in agreement with UNECE's guidance No. 83 and the State Standard Specification of Russia No. 17.2.2.03-87.

\begin{tabular}{lcccc}
\hline & & \multicolumn{3}{c}{ Changes $(\%)$} \\
\cline { 3 - 5 } Vehicle & Excess air coefficient $(\alpha)$ & $\mathrm{CO}$ & $\mathrm{CH}$ & $\mathrm{NO}_{x}$ \\
\hline UAZ-31512 & 0.98 & +2.0 & -35.5 & -26.5 \\
VAZ -2110 & 1.02 & -30.2 & -15.0 & +1.1 \\
VAZ-2110 & $\geq 1.02$ & -27.3 & -18.6 & 0 \\
VAZ -2110 & Idle running & -59.3 & -47.8 & - \\
VAZ -2110 & Overspeed running & -4.8 & -66.7 & - \\
\hline
\end{tabular}

Table 5: Toxic emissions in the cycle of test running with warm engine starting (diesel engine ZIL-645) in agreement with UNECE's guidance No. 49.

\begin{tabular}{|c|c|c|c|c|c|c|}
\hline \multirow[b]{2}{*}{ Diesel fuel } & \multicolumn{3}{|c|}{ Emissions $(\mathrm{g} / \mathrm{kW} \cdot \mathrm{h})$} & \multicolumn{3}{|c|}{ Peak concentration (ppm) } \\
\hline & $\mathrm{CO}$ & $\mathrm{CH}$ & $\mathrm{NO}_{\mathrm{x}}$ & $\mathrm{CO}$ & $\mathrm{CH}$ & $\mathrm{NO}_{\mathrm{x}}$ \\
\hline Without the additive & 3.78 & 0.86 & 9.08 & 720 & 285 & 1275 \\
\hline With the additive & 3.23 & 0.54 & 7.21 & 615 & 190 & 1000 \\
\hline
\end{tabular}




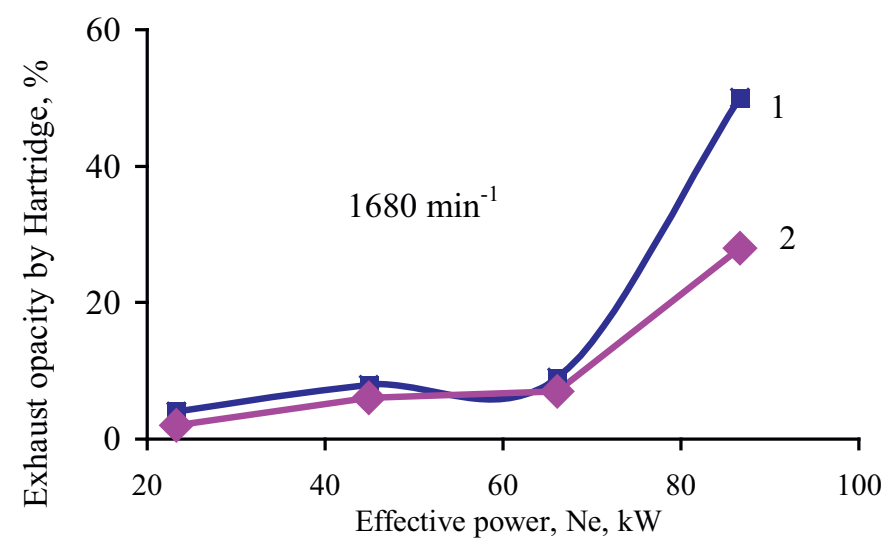

Figure 6: Influence of the additive on the soot emissions: 1 - without the additive and 2 - with the additive.

Table 6: The decrease of the washout time of the tar deposit under the influence of the detergent additives, times.

The additive, concentration in fuel $(\mathrm{mg} / \mathrm{kg})$

\begin{tabular}{ccccc}
\hline The developed additive 9.25 & Afen-1, 250 & Avtomag, 1000 & Paradine-50, 200 & MPA-85, 200 \\
2.33 & 1.60 & 1.50 & 2.41 & 2.34 \\
\hline
\end{tabular}

The author assumes that in addition to solubilizing properties the high effect of the additive is associated with the formation of adsorption layers that prevent the adhesion of tar. The detergent properties of diesel fuel also increase by a factor of 2.33 with the introduction of the additive that reduces the contamination of the fuel injectors.

\subsection{The influence of the additive on cetane number of diesel fuel}

The introduction of the additive into the diesel fuel increases the cetane number linearly to one point when increasing the concentration of the additive into the fuel by $13,875 \mathrm{mg} / \mathrm{kg}$ [16]. Table 7 presents the comparative study of the effectiveness of different additives, which increase the cetane number. It follows from presented data that the developed multifunctional additive increases the cetane number of diesel fuel by four points at a concentration level 17-34 times lower than the commonly used cetane increasing additives and giving a greater cetane number increment at a concentration 10-20 times lower.

\subsection{The influence of the additive on the low temperature properties of diesel fuel}

In countries with severe climates, where a significant decrease in temperature can readily occur, the limiting filterability of diesel fuel, which defines the possibility of its utilization under the low temperatures, is of great importance. The big difference between temperatures of limiting filterability and turbidity is useless, because small crystals going through the filter can plug it, preventing fuel 
Table 7: The influence of different additives on cetane number of diesel fuels.

\begin{tabular}{lcc}
\hline Additive & Concentration $(\%)$ & Cetane number gain \\
\hline 2-Ethylhexyl nitrate & 0.100 & 4 \\
ADX 743 & 0.100 & 5 \\
Cyclohexyl nitrate & 0.200 & 4 \\
Paradine-668 & 0.200 & 4 \\
Lubrisol 8090 & 0.200 & 4 \\
The developed additive & 0.006 & 4 \\
The developed additive & 0.010 & 6 \\
\hline
\end{tabular}

Table 8: The influence of the additive on the low temperature properties of diesel fuel.

\begin{tabular}{lccc}
\hline & \multicolumn{3}{c}{ Decrease of temperature $\left({ }^{\circ} \mathrm{C}\right)$} \\
\cline { 2 - 4 } Diesel fuel & The turbidity & The chilling & The limiting filterability \\
\hline Sample I (chilling point $-7^{\circ} \mathrm{C}$ ) & -4 & -9 & -9 \\
Sample II (chilling point $\left.-14^{\circ} \mathrm{C}\right)$ & 0 & -2 & -9 \\
\hline
\end{tabular}

feeding. At extremely low concentrations in diesel fuel, the additive significantly (at $9^{\circ} \mathrm{C}$ ) lowers the temperature of the limiting filterability (Table 8).

The results can be explained on the basis of concepts about the low temperature properties of fuels, where the increase of dispersiveness of released wax crystals connects with blocking of the crystal growth because of adsorption on the surface of surface-active molecules of the additive.

4.7 The influence of the additive on the antiwear properties of diesel fuels

Antiwear properties of diesel fuel define the resource of injection pumps, which depends on the viscosity of the fuel and the content of the surfactant that adsorbs on the interacting surfaces reducing as a result the coefficient of friction. Deep hydrotreating of diesel fuels reduces their antiwear properties, so it is necessary to introduce into hydrotreated fuels some antiwear additives. The results of testing of the influence of the developed additive on wear-resistant properties (lubricity) of diesel fuel in a rate of static friction are shown on Fig. 7. In Table 9, the data of the influence of antiwear additives known on the world market and the developed one on lubricity are presented for comparison.

\section{CONCLUSION}

It is shown theoretically that the elimination of carbon deposit in the engine will significantly reduce toxic emissions of vehicles, specific fuel consumption, and requirements of vehicles with gasoline engines for octane number of gasoline used. The method of engine carbonization suppression based on the catalytic acceleration of reactions of oxidation and gasification by means of the additive introduced into fuel in the ultra-low quantities was proposed. The application of the additive effectively removes carbon deposit and gives the integrated effect of improving the environmental and operational properties of motor fuels and vehicle characteristics. Using the method developed elimination 


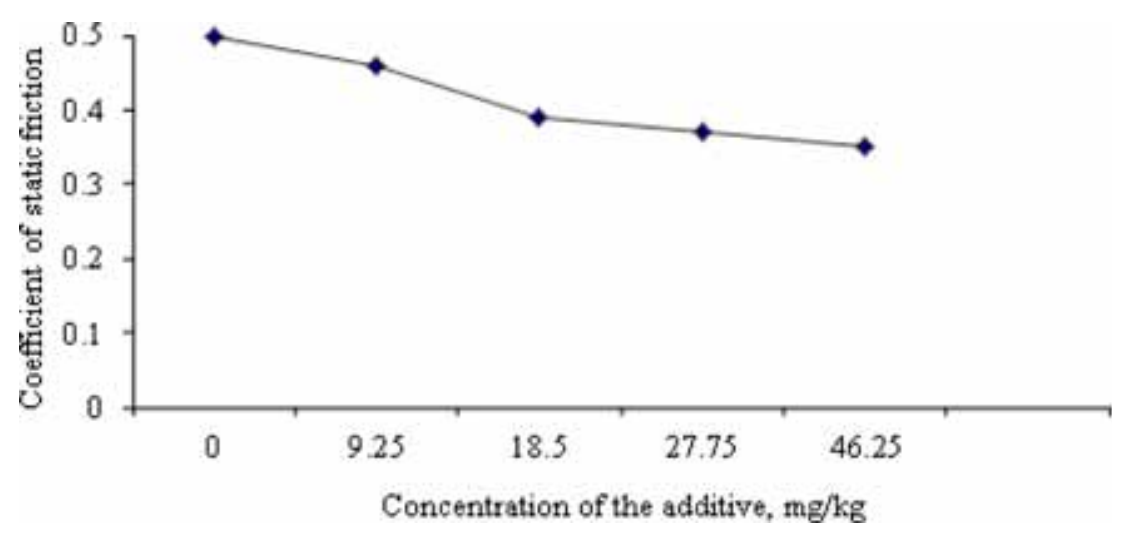

Figure 7: The coefficient of static friction with lubrication of friction pair by diesel fuel (viscosity at $20^{\circ} \mathrm{C}$ equals $1.7 \mathrm{~mm}^{2} / \mathrm{s}$, sulfur content $0.02 \%$ ) with different contents of the additive.

Table 9: The influence of the additives on the coefficient of static friction of steel-steel couple with lubrication by film of diesel fuel, with concentration of additives $25 \mathrm{mg} / \mathrm{kg}$.

\begin{tabular}{lc}
\hline The additive & The coefficient of static friction \\
\hline Without additive & 0.50 \\
Kerokorr LA99 & 0.42 \\
Lubrizol LZ 539N & 0.39 \\
The developed additive & 0.38 \\
\hline
\end{tabular}

of carbon formation in engines provides a cost-effective solution to the problem of the shortage of high octane gasoline in some countries and significantly increases the environmental safety of vehicle operation.

\section{REFERENCES}

[1] Parry, I.W.H. \& Bento, A., Estimating the welfare effect of congestion taxes: the critical importance of other distortions within the transport system. Journal of Urban Economics, 51(2), pp. 339-365, 2002. doi: http://dx.doi.org/10.1006/juec.2001.2248

[2] Gallo, M., A fuel surcharge policy for reducing road traffic greenhouse gas emissions. Transport Policy, 18(2), pp. 413-424, 2011. doi: http://dx.doi.org/10.1016/j.tranpol.2010.11.003

[3] Syunyaev, Z.I., Production, Improvement and the Use of Petroleum Coke [in Russian], Himiya: Moscow, pp. 181-185, 1973.

[4] Prohorov, A.M. (main editor), Physical encyclopaedia, Vol 1, [in Russian], The Great Russian Encyclopedia: Moscow, p. 65, 1988.

[5] Vvedensky, B.A. (main editor), Physical Encyclopedic Dictionary, Vol.5, [in Russian], Soviet Encyclopedia: Moscow, p. 222, 1966.

[6] Prohorov, A.M. (main editor), Physical Encyclopaedia, Vol. 2, [in Russian], The Great Russian Encyclopedia: Moscow, p. 111, 1990. 
[7] Vvedensky, B.A. (main editor), Physical Encyclopedic Dictionary, Vol. 3, [in Russian], Soviet Encyclopedia: Moscow, pp. 24-26, 1963.

[8] Zefirov, N.S. (main editor), Chemical Encyclopaedia, Vol. 4, [in Russian], The Great Russian Encyclopedia: Moscow, p. 528, 1995.

[9] Skoblo, A.I., Molokanov, J.K., Vladimirov, A.I. \& Shchelkunov, V.A., Processes and Equipment of Oil and Gas Processing, and Petrochemistry [in Russian], Third edition, revised and added. Nedra-Business centre: Moscow, pp. 534-544, 2000.

[10] Gruze, V.A. \& Stivens, D.R., Technology of the Oil Refining [in Russian], Himia: Leningrad, p. 414, 1964.

[11] Gureev, A.A. \& Azev, V.S., Automobile Gasolines. Properties and Application [in Russian], Neft i gaz: Moscow, pp. 282-294, 1996.

[12] Kondratiev, V.N., Rate Constants of Gaseous-Phase Reactions: Directory [in Russian], Nauka: Moscow, pp. 228-241, 1970.

[13] Magaril, E.R., Influence of the Quality of Engine Fuels on the Operation and Environmental Characteristics of Vehicles: Monograph [in Russian], KDU: Moscow, 2008.

[14] Magaril, E.R. \& Magaril, R.Z., Motor Fuels [in Russian], Second edition, KDU: Moscow, 2010.

[15] Magaril, E.R. \& Magaril, R.Z., Automobile Fuels: The Problems of Energy Efficiency and Environmental Safety [in Russian], LAP LAMBERT Academic Publishing GmbH \& Co: Saarbrucken, 2012.

[16] Magaril, E., Improving car environmental and operational characteristics using a multifunctional fuel additive. Proc. of 19th Int. Conf. on Modelling, Monitoring and Management of Air Pollution, eds C.A. Brebbia \& J.W.S. Longhurst, WIT Press: Southampton, pp. 373-384, 2011. 